\title{
Occupational irritants and asthma: an Estonian cross-sectional study of 34000 adults
}

\author{
Orianne Dumas ${ }^{1,2}$, Emeline Laurent ${ }^{1,2}$, Jean Bousquett ${ }^{1,3}$, Andres Metspalu ${ }^{4}$, \\ Lili Milani ${ }^{4}$, Francine Kauffmann ${ }^{1,2}$ and Nicole Le Moual ${ }^{1,2}$
}

Affiliations: ${ }^{1}$ Inserm, Centre for Research in Epidemiology and Population Health (CESP), U1018, Respiratory and Environmental Epidemiology Team, F-94807, Villejuif, France. ${ }^{2}$ Univ. Paris-Sud, UMRS 1018, F-94807, Villejuif, France. ${ }^{3}$ University Hospital, Hôpital Arnaud de Villeneuve, Dept of Respiratory Diseases, Montpellier, France. ${ }^{4}$ The Estonian Genome Center, Tartu University, Tartu, Estonia.

Correspondence: Orianne Dumas, Respiratory and Environmental Epidemiology, CESP/U1018 Inserm, 16 Avenue Paul Vaillant Couturier, 94807 Villejuif Cedex, France. E-mail: orianne.dumasdinserm.fr

ABSTRACT Occupational exposures make important contributions to asthma morbidity. The role of low/ moderate level irritant exposures remains unclear. We aimed to determine which occupational exposures are associated with asthma in an eastern European country with low asthma prevalence.

The Estonian Genome Center of University of Tartu collected data from 50077 adults in 2002-2011. Asthma was assessed through a questionnaire regarding diagnosed diseases, current health status and medication. Exposures to 22 agents during the current and longest held jobs were estimated using an asthma-specific job-exposure matrix.

Analyses included 34015 subjects (aged 18-65 years, 67.0\% females), of which 1209 (3.6\%) reported asthma (608 with physician-confirmed diagnosis). After adjusting for age, sex and smoking habits, lifetime occupational exposure to known asthmagens (20.4\%) was significantly associated with physician-diagnosed asthma (OR 1.28, 95\% CI 1.03-1.59), especially high molecular weight agents (flour: OR 2.36, 95\% CI 1.31-4.27; animals: OR 1.62, 95\% CI 1.00-2.60). Exposure to low/moderate levels of irritants (17.4\%) was associated with physician-diagnosed asthma (OR 1.88, 95\% CI 1.48-2.37). More pronounced associations were observed in subjects reporting current treated asthma.

Beyond confirming the effect of known asthmagens (which are well-known, mostly from observations in western countries), the results provide evidence for a role of low/moderate exposure to irritants. This finding, observed in a country with a low prevalence of asthma and atopy, provides new insight into the understanding of asthma heterogeneity.

@ERSpublications

Increased asthma risk was associated with occupational exposure to moderate levels of irritants in an Estonian study http://ow.ly/uti5L

For editorial comments see page 562 .

This article has supplementary material available from www.erj.ersjournals.com

Received: Oct 022013 | Accepted after revision: March 042014 | First published online: April 172014

Support statement: This study was funded by French National Agency for Research (grant number: ANR-PRSP10-IAGO); A. Metspalu and L. Milani received funding from the Estonian Government (grant number: SF0180142s08), Center of Excellence in Genomics (EXCEGEN) and from the University of Tartu (grant number: SP1GVARENG).

Conflict of interest: Disclosures can be found alongside the online version of this article at www.erj.ersjournals.com

Copyright @ERS 2014 


\section{Introduction}

There is a growing interest in asthma due to nonallergic mechanisms [1] in the context of the understanding of asthma heterogeneity [2]. Epidemiological studies have shown that less than half of asthma cases can be related to atopy or attributed to allergen exposures [1], consistent with findings from mechanistic or clinical approaches $[2,3]$.

Occupational asthma is a good model for studying asthma in general [4]. More than 400 agents have been recognised to cause occupational asthma, and new agents are reported each year [5, 6]. Occupational asthma is classified into two different types according to the causative agents and the underlying mechanisms. Most occupational asthmagens are low or high molecular weight sensitisers, which induce asthma through immunological mechanisms $[5,7]$. IgE-mediated mechanisms have been proven for most high and some low molecular weight agents $[5,7]$. The second type of occupational asthma, referred to as "nonimmunologic occupational asthma" [5] or "irritant induced asthma" [8], was first described in relation to a single exposure to high concentrations of irritants. The potential role of repeated low-tomoderate levels of exposure to irritants in occupational asthma is receiving growing attention [8].

As in other eastern European countries that were formerly part of the Soviet Union $[9,10]$, a lower prevalence of atopy and asthma was observed in Estonia compared with western Europe in the 1990s [11, 12]. The degree of westernisation, and associated environmental and lifestyle-related exposures [9-11, 13] were suggested to explain these differences. However, by contrast with most other countries, the rate of asthma and allergy has remained low in Estonia [14]. Although the transitional context of eastern European countries provides interesting opportunities to improve understanding of asthma determinants and heterogeneity, few data have been reported in the past decade, especially in adults. Similarly, most, although not all, epidemiological studies of work-related asthma have been conducted in populations of westernised countries [15-17]; however, the development of a worldwide perspective in work-related lung disease is needed [18].

In 2001, a large ( $~ 50000$ subjects), population-based study was set up by the Estonian Genome Center of University of Tartu (EGCUT) [19]. The primary purpose of this project was genetic research for human health, but asthma and occupations were also investigated.

Taking advantage of the health and environmental data collected in EGCUT, we aimed to determine whether asthma is associated with occupational exposure to: 1) well-known high and low molecular weight asthmagens, and 2) irritants, in this Estonian population.

\section{Materials and methods}

\section{Study population}

The study participants come from the population-based biobank of EGCUT (www.geenivaramu.ee/en/) [19]. Since 2002, the EGCUT has collected genotype, health and lifestyle data from adults living in Estonia. Participants were recruited by general practitioners or nurses/physicians in hospitals. The cohort contained a random selection of patients who were in regular contact with healthcare services and individuals who volunteered to join the cohort following a multimedia campaign. In October 2011, the cohort included 50077 adults. Only subjects aged 18-65 years were included in the analyses (fig. 1). Subjects who had never worked, or those with missing or imprecise job codes, were excluded.

The project was conducted in accordance to the Estonian Gene Research Act and all participants signed an informed consent form.

\section{Variables studied}

A computer-assisted interview was conducted at the doctors' office by general practitioners or other medical personnel. Past diseases ("which kind of disease have you been diagnosed with?") were classified according to the 10th edition of the International Classification of Diseases (ICD-10). The level of reliability of the diagnosis (confirmed by a physician, probable, or possible), current health status and medication (Anatomical Therapeutic Chemical (ATC)) [21] used in the past 2 months were collected. The current and longest-held jobs were recorded according to the International Standard Classification of Occupation 1988.

\section{Asthma definitions}

Ever asthma was determined by the report of a diagnosis of asthma (ICD-10: J45). Subjects with asthma diagnosis confirmed by a physician were classified as having physician-diagnosed asthma. Subjects with asthma who answered "yes" to the question "Do you have asthma now?" were classified as having current asthma. Among subjects with current asthma, those who reported asthma treatment (ATC: R03) in the past 2 months were classified as having current treated asthma. 


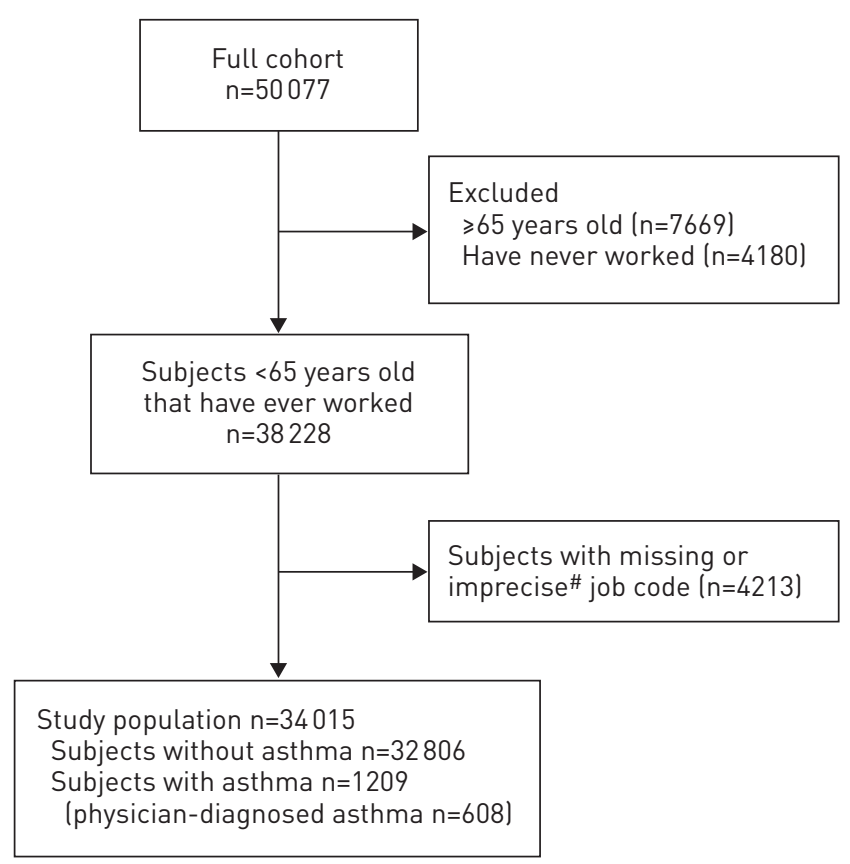

FIGURE 1 Selection of the study population. The Estonian Genome Center of University of Tartu cohort was designed to represent the adult (aged $\geqslant 18$ years) population in Estonia, although participation rates were higher in females, younger/ middle-aged and highly educated subjects (Estonian Genome Center; www.geenivaramu.ee/en/). " : $\leqslant 3$-digit code, these subjects were excluded because of potential increased exposure misclassification when applying the job-exposure matrix [20]. We investigated a potential bias due to their exclusion by comparing them to the included subjects (online supplementary table E1).

\section{Occupational exposure}

The job codes were linked to estimates of exposures to 22 agents using an asthma-specific job-exposure matrix (JEM) [20]. Exposures to 1) 18 known asthmagens, and 2) four work environments with low/ moderate levels of exposure to irritants, or with low levels of exposure to chemicals or allergens, were evaluated. The category "low/moderate levels of exposure to irritants" refers to jobs that are unlikely to involve high concentration or "peak" exposure to irritants (known to induce asthma), but that potentially involve repeated exposure to "common" levels of irritants (which were not considered at risk for asthma when the JEM was set up at the end of the 1990s). The category "low level of exposure to chemicals or allergens" refers to jobs with potential exposure to know asthmagens, but at levels expected to be too low to cause occupational asthma. Exposure (yes/no) to each of the 22 agents was evaluated for the current and longest held jobs. The maximum exposure level over the current and longest held jobs was used to approximate lifetime exposure for each agent (for simplicity, it will be referred to as "lifetime exposure" in subsequent sections).

A list of occupations potentially at risk for asthma were also derived from previous classifications [22]. Current job titles were grouped into 58 categories and compared to a reference group of administrative and service jobs (online supplementary material).

\section{Statistical analyses}

Associations with asthma outcomes were studied for 1) lifetime and current exposure using the broad categories of the asthma JEM (non-exposed, exposed to known asthmagens, only exposed to low levels of irritants or chemicals/allergens), 2) lifetime exposure to the specific agents of the asthma JEM, and 3) the current job category. In all analyses, the exposure category "low levels of irritants or chemicals/allergens" and its subcategories included only jobs not concurrently classified as exposed to known asthmagens. Analyses were performed for specific agents or job categories for which at least five subjects with asthma were exposed [20]. Associations were evaluated by logistic regressions, adjusted for age, sex and smoking habits (never, ex- or current smokers), using SAS 9.1 (SAS Institute Inc., Cary, NC, USA). Correction for multiple testing, using the false discovery rate approach (R package "p.adjust"; The R Project for Statistical Computing, www.r-project.org), was applied to the analysis of job categories. 


\section{Results}

\section{Demographic characteristics}

Among the 34015 subjects selected for the analyses (mean age 41.5 years and $67.0 \%$ female) (table 1), asthma was reported by $1209(3.6 \%)$ subjects. Of whom, 50.3\% $(\mathrm{n}=608)$ had physician-diagnosed asthma, $73.9 \%$ had current asthma and $51.9 \%$ reported use of asthma medication in the past 2 months. Subjects with asthma were less often employed at interview (76.0\%) than subjects without asthma $(81.2 \%, \mathrm{p}<0.001)$, and the difference remained significant after adjusting for age and sex. Among subjects not currently working, subjects with asthma were more often disability pensioners $(35.2 \%)$ than subjects without asthma $(24.0 \%, \mathrm{p}=0.01$ after adjusting for age and sex).

\section{Exposure to asthmagens and irritants}

$20 \%$ of the subjects had ever been exposed to known asthmagens. The most frequent exposures were latex (5.4\%), highly reactive chemicals $(4.3 \%)$, textile production $(4.2 \%)$ and agriculture (3.8\%) (online supplementary fig. E1). 27\% of the subjects had ever been exposed to low levels of irritants or chemicals/ allergens (and not to known asthmagens): 17.4\% were exposed to low levels of irritants (combustion particles or fumes, environmental tobacco smoke, or irritant gases or fumes) and $16.3 \%$ to low levels of chemicals/allergens.

Females were exposed to high molecular weight (HMW) agents and mixed environments significantly more often than males ( $13.6 \%$ versus $3.6 \%$ and $10.6 \%$ versus $3.6 \%$, respectively), while males were more often exposed to irritant peaks (6.5\% versus $0.5 \%$ ), low-level irritants (at least one of the three groups: $40.5 \%$ versus $11.2 \%$ ), and low levels of chemicals/allergens (21.8\% versus $17.3 \%)$.

\section{Occupational exposures and asthma outcomes}

Overall lifetime exposure to known asthmagens was more frequent among subjects with asthma than among those without asthma, although the association did not reach significance $(21.8 \%$ versus $20.4 \%$, $\mathrm{p}=0.08$; adjusted OR 1.12, 95\% CI 0.97-1.30) (fig. 2a). However, a significant positive association was observed with physician-diagnosed asthma (adjusted OR 1.28, 95\% CI 1.05-1.58). Higher significant odds ratios were observed for those with current physician-diagnosed asthma and current treated physiciandiagnosed asthma.

Lifetime exposure to low levels of irritants or chemicals/allergens was more frequent among subjects with asthma than among those without asthma $(29.0 \%$ versus $27.1 \%, \mathrm{p}=0.06$; adjusted OR $1.19,95 \%$ CI 1.03-1.37). More pronounced and significant associations were observed for physician-diagnosed asthma, current physician-diagnosed asthma and current treated physician-diagnosed asthma, with ORs increasing across asthma definitions from 1.76 to 1.99 (fig. 2b). Consistent results with higher odds ratios were observed in analyses of current occupational exposure.

A significant association between physician-diagnosed asthma and lifetime occupational exposure to known asthmagens was observed in females (OR 1.33, 95\% CI 1.05-1.68) and not in males (OR 1.14, 95\% CI 0.68-1.91; interaction $\mathrm{p}=0.53)$. The associations observed for low levels of exposure to irritants or chemicals/allergens were similar in males and females (online supplementary tables E2 and E3).

\section{TABLE 1 Description of the study population according to asthma diagnosis}

\begin{tabular}{|c|c|c|c|c|c|c|}
\hline & Total & No asthma & Asthma & p-value $\#$ & $\begin{array}{l}\text { Physician-diagnosed } \\
\text { asthma }\end{array}$ & p-value $\#$ \\
\hline Subjects $\mathrm{n}$ & 34015 & 32806 & 1209 & & 608 & \\
\hline Females & $6 \overline{7} .0$ & $6 \overline{6} .9$ & $6 \overline{9} .5$ & 0.06 & $6 \overline{7} .8$ & 0.6 \\
\hline \multicolumn{7}{|l|}{ Smoking habits $\pi$} \\
\hline Never smokers & 54.2 & 54.3 & 52.0 & & 51.5 & \\
\hline Current asthma & & & 73.9 & & 91.1 & \\
\hline Current treated asthma & & & 51.9 & & 67.1 & \\
\hline Currently working & 81.0 & 81.2 & 76.0 & $<0.001$ & 75.2 & $<0.001$ \\
\hline
\end{tabular}

Data are presented as mean \pm SD or $\%$, unless otherwise stated. " : comparison by Chi-squared or t-tests between subjects without asthma and subjects with asthma and physician-diagnosed asthma, respectively; ": missing data for $n=13$ subjects. 
$\diamond$ Ever asthma

$\triangle$ Current physician-diagnosed asthma

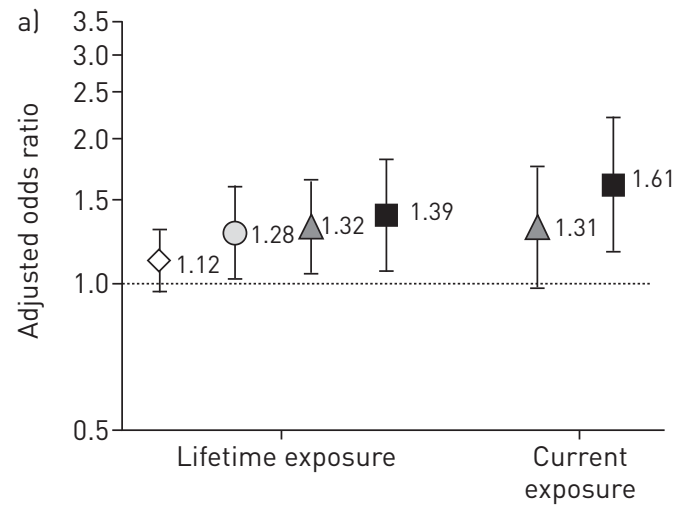

Exposed with asthma $\mathrm{n}$

$\begin{array}{llll}263 & 130 & 121 & 90\end{array}$
6955
Physician-diagnosed asthma

Current treated physician-diagnosed asthma

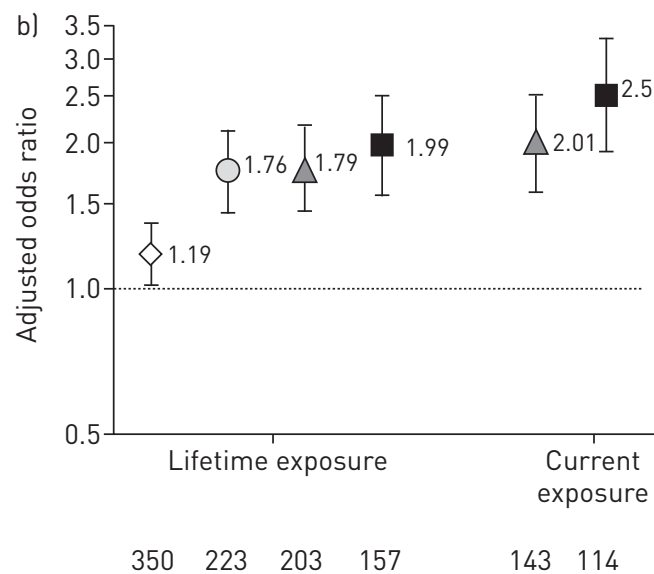

FIGURE 2 Associations between lifetime occupational exposure (i.e. during the longest held job or during the current job) and current occupational exposure to a) known asthmagens and b) low levels of irritants or chemicals/allergens (and not known asthmagens), and asthma according to asthma definition. Odds ratios are adjusted for age, sex and smoking habits. Error bars represent 95\% confidence intervals.

\section{Exposure to known asthmagens and asthma outcomes}

The main analysis evaluating the associations between exposure to each specific asthmagen and asthma was focused on lifetime occupational exposure and physician-diagnosed asthma (table 2). Among known asthmagens, significant associations were observed for four HMW agents (flour, enzymes, animals and bioaerosols) and two mixed environments (agriculture and textile production). For low molecular weight (LMW) agents, ORs were close to or below the unity.

These results were confirmed using different definitions of occupational exposure and asthma outcomes. For the associations between current exposures and current treated physician-diagnosed asthma, higher odds ratios were observed: 1.82 (95\% CI 1.22-2.70) for exposure to HMW agents and 2.52 (95\% CI 1.65-3.84) for mixed environments (with odds ratios reaching 3.81 and 3.44 for exposure to animals and agriculture, respectively). An additional significant association was observed for exposure to latex (OR 1.67, 95\% CI 1.03-2.71). Overall, odds ratios remained similar for exposure to LMW agents but a suggestive (nonsignificant) association was observed for exposure to industrial cleaning/disinfecting products (OR $1.80,95 \%$ CI $0.83-3.91)$.

In sex-stratified analyses (online supplementary tables E2 and E3), associations were observed for exposure to animal antigens in males, and for exposure to flour, enzymes, work in textile production and in agriculture in females.

\section{Low levels of exposure to irritants or to chemicals/allergens (and no exposure to known asthmagens) and asthma outcomes}

A significantly increased risk of physician-diagnosed asthma was observed in subjects ever exposed to low levels of chemicals/allergens, and to combustion particles/fumes and irritant gases/fumes (table 2). Similar results were observed in males and females (online supplementary tables E2 and E3). Odds ratios $>2$ were observed when considering current exposures and current treated physician-diagnosed asthma: 2.63 (95\% CI 1.96-3.53) for low levels of chemicals/allergens, 2.86 (95\% CI 1.73-4.73) for combustion particles/fumes and 2.83 (95\% CI 1.96-4.09) for irritant gases/fumes.

Associations between asthma and low levels of exposure to irritants (combustion particles/fumes, irritant gases/fumes or environmental tobacco smoke) were examined specifically. The odds ratios were 1.88 (95\% CI 1.48-2.37) and 2.86 (95\% CI 2.08-3.94) for the associations between lifetime exposure and physiciandiagnosed asthma, and between current exposure and current treated physician-diagnosed asthma, respectively. After excluding those with concurrent exposure to low levels of chemicals/allergens, the odds ratios remained high and significant (1.82 (95\% CI 1.34-2.45) and 2.44 (95\% CI 1.57-3.80), respectively). The most frequent occupations with low levels of exposure to irritants were: building workers, heavy lorry/ car/bus drivers, carpenters/joiners and cabinet makers, and machinery mechanics (jobs with $>90 \%$ male 
TABLE 2 Associations between lifetime ${ }^{\#}$ specific occupational exposures and physician-diagnosed asthma

\begin{tabular}{|c|c|c|c|c|}
\hline & Subjects $\mathrm{n}$ & $\begin{array}{l}\text { Physician-diagnosed } \\
\text { asthma } \mathrm{n}(\%)\end{array}$ & OR & Adjusted OR ${ }^{\pi}(95 \% \mathrm{Cl})$ \\
\hline Unexposed $^{+}$ & 17503 & $255(1.5)$ & 1 & 1 \\
\hline \multicolumn{5}{|l|}{ Known asthmagens } \\
\hline HMW agents & 3442 & $73(2.1)$ & 1.47 & $1.40(1.07-1.82)$ \\
\hline Animals & 699 & $19(2.7)$ & 1.89 & $1.62(1.00-2.60)$ \\
\hline Flour & 351 & $12(3.4)$ & 2.39 & $2.36(1.31-4.27)$ \\
\hline Enzymes & 287 & $9(3.1)$ & 2.19 & $2.14(1.08-4.22)$ \\
\hline Latex & 1791 & $30(1.7)$ & 1.15 & $1.15(0.78-1.69)$ \\
\hline Bioaerosols & 1042 & $26(2.5)$ & 1.73 & $1.51(1.00-2.28)$ \\
\hline Drugs $^{\S}$ & 741 & $9(1.2)$ & 0.83 & $0.85(0.43-1.66)$ \\
\hline LMW agents & 2125 & $26(1.2)$ & 0.84 & $0.84(0.56-1.26)$ \\
\hline Highly reactive chemicals & 1417 & $20(1.4)$ & 0.97 & $0.97(0.61-1.53)$ \\
\hline Cleaning/disinfecting products & 559 & $9(1.6)$ & 1.11 & $1.02(0.52-2.01)$ \\
\hline Metals & 801 & $6(0.7)$ & 0.51 & $0.51(0.22-1.16)$ \\
\hline Mixed environments & 2767 & $64(2.3)$ & 1.60 & $1.48(1.12-1.96)$ \\
\hline Textile production & 1388 & $30(2.2)$ & 1.49 & $1.47(1.00-2.17)$ \\
\hline Agriculture & 1259 & $34(2.7)$ & 1.88 & $1.63(1.13-2.35)$ \\
\hline High irritant peaks & 837 & $8(1.0)$ & 0.65 & $0.72(0.34-1.50)$ \\
\hline \multicolumn{5}{|l|}{$\begin{array}{l}\text { Low levels of exposure to irritants or to chemicals/ } \\
\text { allergens only }\end{array}$} \\
\hline Low level of exposure to chemicals/allergens & 5454 & $132(2.4)$ & 1.68 & $1.72(1.39-2.14)$ \\
\hline Combustion particles/fumes & 2371 & $62(2.6)$ & 1.82 & $1.77(1.26-2.48)$ \\
\hline Environmental tobacco smoke & 514 & $5(1.0)$ & 0.66 & $0.94(0.38-2.31)$ \\
\hline Irritant gases/fumes & 3096 & $81(2.6)$ & 1.82 & $2.04(1.55-2.68)$ \\
\hline Low level of exposure to irritants only $f^{f}$ & 3651 & $91(2.5)$ & 1.73 & $1.82(1.34-2.45)$ \\
\hline \multicolumn{5}{|c|}{$\begin{array}{l}\text { Total } n=33414 . \text { Bold font indicates statistical significance. HMW: high molecular weight; LMW: low molecular weight. }{ }^{\#} \text { : exposure during the } \\
\text { longest-held job or current job. }{ }^{\circ} \text { : evaluated by logistic regressions adjusted for age, sex and smoking habits. }{ }^{+} \text {: reference group who were no } \\
\text { exposed to any of the } 22 \text { agents of the job-exposure matrix (JEM) during the longest held job and current job. }{ }^{5} \text { : pharmaceutical products mas } \\
\text { include both HMW and LMW antigens. }{ }^{f} \text { : those exposed to irritants (combustion particles/fumes, irritant gases/fumes or environmental tobacco } \\
\text { smoke), after excluding those who were further exposed to low levels of chemicals/allergens; analyses were performed for specific agents for } \\
\text { which at least five subjects with asthma were exposed, i.e. } 15 \text { out of the } 22 \text { agents of the asthma JEM. }\end{array}$} \\
\hline
\end{tabular}

workers); cleaners in offices or hotels (jobs with $>90 \%$ female workers) and waiters/bartenders $(\sim 60 \%$ female workers).

\section{Job categories}

Among the 58 job categories classified as potentially at risk of asthma, 20 job categories were analysed (five or more subjects with asthma exposed). Significant, positive associations were observed with current physician-diagnosed asthma for 13 job categories (all remained significant after correction for multiple comparisons) (table 3). Among the job categories associated with asthma, six were largely held by females $(>80 \%)$, including cleaning and health-related occupations, textile workers, hand packers and dairy/ livestock producers, while five job categories were mostly held by males $(>90 \%)$, including mechanical workers, electricians, motor vehicle drivers and building workers. A positive association was also observed for wood treaters and for "other craft and trade workers" ( $\sim 45 \%$ female workers). A significant negative association with asthma was observed for teaching professionals.

\section{Population-attributable risk}

The results from the current study yield a population-attributable risk estimate of $4.7 \%$ for known asthmagens and physician-diagnosed asthma (using the formula: (OR-1)/OR $\times$ exposure frequencycases). For low levels of exposure to irritants or chemicals/allergens and physician-diagnosed asthma, the estimated population-attributable risk was $15.8 \%$. Considering exposure to any of the three categories of low level exposure to irritants only (combustion particles/fumes, irritant gases/fumes or environmental tobacco smoke), the population-attributable risk was $6.7 \%$. 


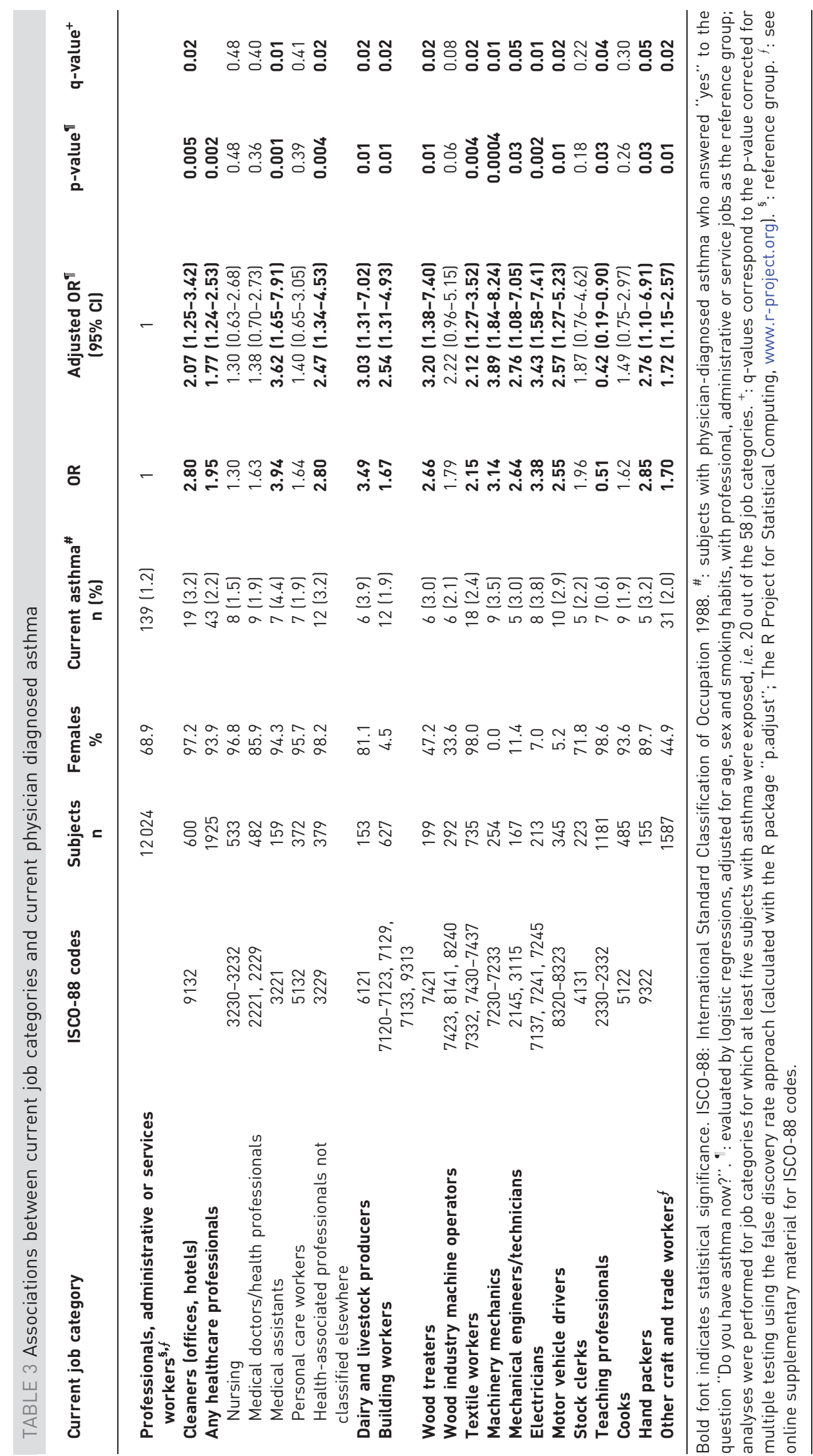




\section{Discussion}

In this large study conducted in subjects from Estonia, the role of known occupational asthmagens, mainly HMW and mixed environments was shown, extending observations mostly from western countries of occupational determinants of asthma. Importantly, the still-disputed role of moderate exposure to irritants was clearly shown in subjects living in a country with a low prevalence of asthma and atopy.

The EGCUT cohort was not specifically designed for research on respiratory health, and asthma definition was based on a general health questionnaire. It has been suggested that differences in diagnostic practices in relation to the influence of the former Soviet Union partly explain the lower prevalence of physiciandiagnosed asthma in Estonia compared with western European countries [23]. However, economic, environmental and lifestyle conditions have been evolving rapidly in Estonia since the fall of the socialist system [24]. Increased asthma awareness and changes in diagnostic procedures have been emphasised, and an increase in the prevalence of physician-diagnosed asthma has already been observed in children in 2001-2002 [24]. The EGCUT began in 2002, and nearly three-quarters of the participants were recruited after 2008, i.e. $>15$ years after the end of the Soviet era and after Estonia entered the European Union in 2004. Nonetheless, asthma may remain underdiagnosed in our population [23], leading to a potential misclassification bias. However, one strength of the current study was the relatively precise data on asthma (diagnosis confirmation by a physician, current disease status and use of asthma medication) for such a large population. Our results were systematically confirmed, with increasing odds ratios, when using more stringent definitions of asthma outcomes. Finally, females, younger/middle-aged and highly educated subjects were overrepresented in this cohort compared with the Estonian general population. However, with the main objective of EGCUT being stated as the study of genetic determinants of health, it is unlikely that occupational health had an influence on participation that led to major bias.

Occupational exposures were evaluated using an asthma-specific JEM, which was designed, based on expert knowledge at the end of the 1990s, to link job codes to exposure to agents potentially a risk for asthma or respiratory health. The asthma-specific JEM has been used in several previous studies and populations [25]. This JEM was not specifically designed for Estonia and an expert re-evaluation step, recommended to improve exposure assessment (but likely to be more important in small studies), could not be applied here as the information on jobs was limited. However, the JEM has already been used in a large study without including the expert re-evaluation step [22]. The elevated odds ratios observed for well-known HMW allergens and for work environments with multiple hazardous exposures (agriculture and textile production) confirm the relevance of the JEM in this population. By contrast, no association was suggested for exposure to LMW agents. Studying job categories is a more sensitive and exploratory approach, complementing the JEM. For instance, for exposures to cleaning/disinfecting products and to wood dust, no associations were observed with the JEM, while increased asthma risks, consistent with existing literature $[7,26,27]$, were suggested in the analysis of job categories. For mechanics, electricians and hand packers, the observed associations were similar to previous studies [16,27], although the specific hazardous agent(s) remain unknown. A refined exposure assessment taking into account the specificities of exposure conditions in Estonia, and considering relevant exposure windows in relation to the historical context, may be useful in future studies.

In the current analysis, we also observed pronounced associations for irritants, the role of which in asthma is less established. For the associations between asthma outcomes and low/moderate occupational exposure to irritants only, we found odds ratios that were as high as those for well-known HMW asthmagens. While the role of irritants in work-exacerbated asthma is established $[28,29]$, whether repeated low dose exposures to irritants may induce new-onset asthma remains a topic of discussion [8]. In clinical studies, the lack of objective tests (specific inhalation challenges) for irritants hampers the diagnosis of low-dose irritantinduced occupational asthma cases, who may be misclassified as having work-exacerbated asthma [29]. Results of epidemiological studies are, thus, of particular interest. In the current study, the cross-sectional design and the lack of reliable information on age at asthma onset prevent strong conclusions on the effect of irritants on new-onset asthma. However, the associations between irritant exposures and asthma were relatively strong, with increased odds ratios for more specific definitions of asthma outcome. In a recent longitudinal study of Norwegian smelters, dust exposure was associated with incidence of work-related asthma-like symptoms [30]. The exposure level was low to moderate and further exposure to sensitisers was unlikely. In a British longitudinal study [16], occupational exposure to environmental tobacco smoke (evaluated by the same asthma-specific JEM [20]) was associated with adult-onset asthma. In a Taiwanese case-control study [17], also using this asthma-specific JEM [20], associations were observed between exposure to irritant peaks and asthma without atopy, but results for lower levels of exposure to irritants were not reported. Finally, the growing literature on the relationship between cleaning exposures and asthma suggests a prominent role for irritants $[16,26,31]$. 
Studies in European populations using the same JEM have not consistently found elevated risks of asthma associated with the same categories of irritant exposures [16, 22]. A healthy worker effect, potentially more pronounced for irritant exposures [32], may partly prevent evidence for their role. In the current study, the odds ratios were relatively elevated and generally higher for current exposure, suggesting that the results were not strongly affected by a healthy worker effect.

The historical context of the population has to be considered to interpret the current results regarding the role of exposure to low/moderate levels of irritants. Almost all subjects (99.8\%) were born before 1991, i.e. under Soviet conditions, and were, thus, exposed in their first years of life, and for a large majority throughout their childhood, to an environment and lifestyle likely to be protective against the development of allergic diseases in childhood and potentially later in life $[9-11,13]$. In studies conducted in children, wheezing was less associated with atopy in Estonia and in Russian Karelia compared with Sweden or Finland [9, 33]. Precise data are lacking in the literature (especially in adults) and no allergy marker was available in the current study. Despite this, indirect arguments suggest that nonallergic asthma might play a more prominent role than allergic asthma in this Estonian cohort compared with western European populations. This might partly explain the pronounced associations between asthma and occupational exposure to low/moderate levels of irritants in this Estonian cohort, while results were more contrasting in other populations.

The mechanisms of irritant-induced asthma remain poorly understood. Irritant exposures can provoke injuries to the bronchial epithelium, which would lose its protective properties [5]. An increased airway permeability caused by irritant exposures may facilitate allergens crossing the epithelium [5, 18]. Concomitant workplace exposure to irritants and allergens would, thus, be associated with higher risk of asthma. In the current study, when considering jobs exposed to low levels of irritants only, odds ratios remained high and significant. Occupational asthma is a good model for the understanding of asthma in general. Genes expressed in the epithelium have been found to be associated with asthma following agnostic approaches [34]. It is of interest to observe that the results of occupational studies on irritants are consistent with the increasing emphasis on the defects in epithelial barriers hypothesis in asthma.

In conclusion, our findings contribute to increasing evidence for a role of repeated low-to-moderate exposures to irritants in asthma onset, which has implications in clinical practice as irritants should be more widely considered as potential causative agents. Moreover, by showing high risk of asthma associated with irritant exposures in this Estonian population with a low prevalence of asthma and atopy, the current analysis provides new insight into the understanding of asthma and its heterogeneity. In that respect, our results support further studies of work-related asthma in various population contexts.

\section{Acknowledgements}

The authors thank all those who participated in setting up the EGCUT cohort, including those involved in the recruitment of the participants and data management. The authors are especially grateful to Kairit Mikkel (The Estonian Genome Center, Tartu University, Tartu, Estonia). They are indebted to all the individuals who participated, without whom that study would not have been possible.

\section{References}

1 Douwes J, Brooks C, van Dalen C, et al. Importance of allergy in asthma: an epidemiologic perspective. Curr Allergy Asthma Rep 2011; 11: 434-444.

Wenzel SE. Asthma phenotypes: the evolution from clinical to molecular approaches. Nat Med 2012; 18: 716-725. Woodruff PG, Modrek B, Choy DF, et al. T-helper type 2-driven inflammation defines major subphenotypes of asthma. Am J Respir Crit Care Med 2009; 180: 388-395.

4 Malo JL, Newman-Taylor A. The history of research on asthma in the workplace - development, victories and perspectives. In: Sigsgaard T, Heederik D, eds. Occupational Asthma. Basel, Birkhäuser/Springer Verlag AG, 2010; pp. $1-15$.

5 Maestrelli P, Boschetto P, Fabbri LM, et al. Mechanisms of occupational asthma. J Allergy Clin Immunol 2009; 123: 531-542.

6 Lemiere C, Ameille J, Boschetto P, et al. Occupational asthma: new deleterious agents at the workplace. Clin Chest Med 2012; 33: 519-530.

Malo JL, Chan-Yeung M. Agents causing occupational asthma. J Allergy Clin Immunol 2009; 123: 545-550.

Labrecque M. Irritant-induced asthma. Curr Opin Allergy Clin Immunol 2012; 12: 140-144.

von Hertzen L, Mäkelä MJ, Petäys T, et al. Growing disparities in atopy between the Finns and the Russians: a comparison of 2 generations. J Allergy Clin Immunol 2006; 117: 151-157.

10 Laatikainen T, von Hertzen L, Koskinen JP, et al. Allergy gap between Finnish and Russian Karelia on increase. Allergy 2011; 66: 886-892.

11 Jõgi R, Janson C, Björnsson E, et al. Atopy and allergic disorders among adults in Tartu, Estonia compared with Uppsala, Sweden. Clin Exp Allergy 1998; 28: 1072-1080.

12 Variations in the prevalence of respiratory symptoms, self-reported asthma attacks, and use of asthma medication in the European Community Respiratory Health Survey (ECRHS). Eur Respir J 1996; 9: 687-695.

13 Brooks C, Pearce N, Douwes J. The hygiene hypothesis in allergy and asthma: an update. Curr Opin Allergy Clin Immunol 2013; 13: 70-77. 
To T, Stanojevic S, Moores G, et al. Global asthma prevalence in adults: findings from the cross-sectional world health survey. BMC Public Health 2012; 12: 204.

15 Torén K, Blanc PD. Asthma caused by occupational exposures is common - a systematic analysis of estimates of the population-attributable fraction. BMC Pulm Med 2009; 9: 7.

16 Ghosh RE, Cullinan P, Fishwick D, et al. Asthma and occupation in the 1958 birth cohort. Thorax 2013; 68: 365-371.

17 Wang TN, Lin MC, Wu CC, et al. Risks of exposure to occupational asthmogens in atopic and nonatopic asthma: a case-control study in Taiwan. Am J Respir Crit Care Med 2010; 182: 1369-1376.

18 Tarlo SM, Malo JL. An official ATS proceedings: asthma in the workplace: the Third Jack Pepys Workshop on Asthma in the Workplace: answered and unanswered questions. Proc Am Thorac Soc 2009; 6: 339-349.

19 Metspalu A. The Estonian genome Project. Drug Develop Res 2004; 62: 97-101.

20 Kennedy SM, Le Moual N, Choudat D, et al. Development of an asthma specific job exposure matrix and its application in the epidemiological study of genetics and environment in asthma (EGEA). Occup Environ Med 2000; 57: 635-641.

21 WHO Collaborating Centre for Drug Statistics Methodology. Guidelines for ATC classification and DDD assignment. Oslo, WHO Collaborating Centre for Drug Statistics Methodology, 2010.

22 Le Moual N, Kennedy SM, Kauffmann F. Occupational exposures and asthma in 14,000 adults from the general population. Am J Epidemiol 2004; 160: 1108-1116.

23 Pallasaho P, Meren M, Raukas-Kivioja A, et al. Different labelling of obstructive airway diseases in Estonia, Finland, and Sweden. Eur J Epidemiol 2005; 20: 975-983.

24 Annus T, Riikjärv MA, Rahu K, et al. Modest increase in seasonal allergic rhinitis and eczema over 8 years among Estonian schoolchildren. Pediatr Allergy Immunol 2005; 16: 315-320.

25 Centre de Recherches en épidémiologie et Santé des Populations, Equipe d'épidémiologie Respiratoire et Environnementale. Estimating occupational risks for asthma in epidemiology: asthma-specific job exposure matrix. http://cesp.vjf.inserm.fr/asthmajem/index.htm Date last accessed: September 30, 2013. Date last updated: March 21, 2011.

26 Zock JP, Vizcaya D, Le Moual N. Update on asthma and cleaners. Curr Opin Allergy Clin Immunol 2010; 10: $114-120$.

27 Kogevinas M, Zock JP, Jarvis D, et al. Exposure to substances in the workplace and new-onset asthma: an international prospective population-based study (ECRHS-II). Lancet 2007; 370: 336-341.

28 Henneberger PK, Redlich CA, Callahan DB, et al. An official American Thoracic Society statement: workexacerbated asthma. Am I Respir Crit Care Med 2011; 184: 368-378.

29 Lemiere C, Bégin D, Camus M, et al. Occupational risk factors associated with work-exacerbated asthma in Quebec. Occup Environ Med 2012; 69: 901-907.

30 Søyseth V, Johnsen HL, Henneberger PK, et al. The incidence of work-related asthma-like symptoms and dust exposure in Norwegian smelters. Am J Respir Crit Care Med 2012; 185: 1280-1285.

31 Lillienberg L, Andersson E, Janson C, et al. Occupational exposure and new-onset asthma in a population-based study in Northern Europe (RHINE). Ann Occup Hyg 2013; 57: 482-492.

32 Dumas O, Le Moual N, Siroux V, et al. Work related asthma. A causal analysis controlling the healthy worker effect. Occup Environ Med 2013; 70: 603-610.

33 Annus T, Björkstén B, Mai XM, et al. Wheezing in relation to atopy and environmental factors in Estonian and Swedish schoolchildren. Clin Exp Allergy 2001; 31: 1846-1853.

34 Holgate ST, Roberts G, Arshad HS, et al. The role of the airway epithelium and its interaction with environmental factors in asthma pathogenesis. Proc Am Thorac Soc 2009; 6: 655-659. 